\title{
Pathological findings in three cases of ataxia-telangiectasia
}

\author{
SABINA J. STRICH \\ From the Department of Neuropathology, Institute of Psychiatry, \\ the Maudsley Hospital, London
}

Ataxia-telangiectasia is a familial cerebellar degeneration of childhood associated with telangiectases and frequent infections of the lungs and air sinuses. It was first described by Louis-Bar in 1941, but it has only become more widely known since Boder and Sedgwick drew attention to the condition with its peculiar and stereotyped symptoms in several papers (Boder and Sedgwick, 1958, 1963, and 1964). The clinical features of some 100 cases have now been recorded but only about a dozen necropsies have been reported. This paper presents the findings in three more necropsies, including some pathological features which have not been described before.

\section{MATERIAL AND METHODS}

The brain, spinal cord, spinal ganglia, samples from peripheral nerves and muscles, and from other organs were fixed in $4 \%$ formaldehyde in $10 \%$ saline. Numerous blocks were taken and embedded in paraffin wax. In addition representative portions of the central nervous system from cases 2 and 3 were embedded in celloidin.

Frozen sections from nervous tissue were stained for lipids with oil-red-O or Sudan black. Frozen sections of muscle were stained for nerve fibres by the Schofield method (1960). Paraffin and celloidin sections were stained with haematoxylin and eosin, haematoxylin and van Gieson's mixture, cresyl violet, luxol-fast-blue (with cresyl violet) or Heidenhein's method for myelin, Holzer's method and Mallory's phosphotungstic acid method for glial fibres; nerve fibres were stained by the Palmgren method (1948) in paraffin sections and by the Gros-Bielschowsky method in celloidin sections. Sections from selected blocks were stained with the periodic acidSchiff technique.

\section{CLINICAL AND NECROPSY FINDINGS IN THREE CASES}

CASE 1 C.C., a boy aged 15 (Maudsley no. 3433), was normal until the age of 4 when, following measles, he had his first attack of otitis media. At this time his gait was noted to be unsteady. By the time he was 6 years old, he had had many attacks of otitis media, sinusitis, and lung infection. Neurological examination showed severe cerebellar ataxia, dysarthria, and nystagmus. Power, tone, and sensation in the limbs were normal. Athetoid movements of the hands were noted. The tendon reflexes varied from day to day, but were present. By the age of 10 he was unable to walk because of severe incoordination though there was no loss of power of the limbs. His intellectual performance had deteriorated and he had developed a mask-like face and difficulty with conjugate deviation of the eyes. Athetoid movements and myoclonic jerks were evident. The neurological signs fluctuated and were always more marked during episodes of infection. At the age of 13 telangiectasia of the bulbar conjunctivae (first diagnosed as conjunctivitis) was noted and later telangiectases appeared on the ears, the centre of the face, and the shoulders. He was very small for his age and there were no signs of puberty. Sensation and sphincter control were normal throughout. His skin and mouth were always dry. He became very wasted and weak and the tendon reflexes were absent on his last admission. He died from lung infection when he was 15.

Family history The patient's elder brother and sister are well. No other members of the family are affected.

Investigations The cerebrospinal fluid was normal on several occasions. At the age of 7 serum $\gamma$-globulin was $200 \mathrm{mg}$. $/ 100 \mathrm{ml}$. (normal). At the age of 11 serum $\gamma$ globulin was only $0.3 \mathrm{mg} . / 100 \mathrm{ml}$. and he was treated with weekly injections of pooled $\gamma$-globulin which seemed to reduce the frequency of infections. The levels of plasma iron, copper, and ceruloplasmin were normal.

Necropsy findings The body was small and wasted. There were no secondary sexual characteristics, the testes were undescended. Telangiectases were present on the bulbar conjunctivae, the ears, the centre of the face, and the shoulders. The thymus weighed $2.4 \mathrm{~g}$. The tracheobronchial lymph nodes were much enlarged. There was bilateral confluent bronchopneumonia. The liver was enlarged (weight 1,080 g.) and ochre coloured. The other organs appeared normal. There was an abnormality of the upper cervical vertebrae. The gap between the edge of the foramen magnum and the atlas and between the atlas and axis was large. The atlas was unusually long and broad and had prominent articular surfaces. The brain weighed $1,480 \mathrm{~g}$. fresh. The meninges were very congested. The cerebellum was small and firm. Coronal sections through the fixed cerebral hemispheres showed normal sized ventricles; grey and white matter looked normal but were congested. The spinal cord showed atrophy of the posterior columns especially of the fasciculus gracilis. 
CASE 2 L.M., a girl aged 11 (Maudsley no. 3298), was referred to hospital at the age of 20 months because of an unsteady gait. Shortly afterwards drooling of saliva began and persisted all her life. At the age of 5 she had wellmarked cerebellar ataxia with intention tremor, dysarthria, and nystagmus. She had a mask-like face but a slow and charming smile. She had a stooping posture. Athetoid movements of the arms were present. From then on there was progressive deterioration though the neurological signs fluctuated, being more marked during periods of infection. By the age of 10 the patient was unable to walk unaided or to dress herself because of incoordination and some muscle weakness. Strabismus was noted. Her intellectual performance had deteriorated. Sensation remained normal and the tendon reflexes were present though they became sluggish towards the end of the illness. At the age of 8 years telangiectases appeared on the bulbar conjunctivae; the skin, especially round the eyes, became pigmented and her hair began to go grey.

When 8 months old she had severe whooping cough and at 14 months she had measles and pneumonia. Later she had chickenpox and herpes zoster. During the rest of her life she had numerous attacks of pneumonia, otitis media, and sinusitis; bronchiectasis developed. At the age of 6 she had pulmonary tuberculosis. A Mantoux test at the time was positive at $1: 1,000$ but became negative after treatment of the tuberculous infection. She died aged 11 of lung infection and bilateral pneumothorax.

Family history Two elder siblings are normal. No other member of the family is affected.

Investigations The cerebrospinal fluid was normal on several occasions. The electroencephalogram was normal. A serum $\gamma$-globulin deficiency, particularly of $\gamma$-Aglobulin was found.

\begin{tabular}{lrrr} 
Gamma Globulins (mg./100 ml.) & $\gamma G$ & $\gamma A$ & $\gamma M$ \\
\hline At 9 years & 1120 & 60 & 100 \\
At 11 years & 280 & $<1$ & 60 \\
Reference serum & $>600$ & 160 & 60
\end{tabular}

Necropsy findings The body was that of a very small and wasted girl. The scalp hair was grey and thin. There were telangiectases on the bulbar conjunctivae. There was a pneumothorax bilaterally, bronchiectasis of the lower lobe of the left lung, and a necrotic granuloma in the right lung. The paratracheal lymph nodes were enlarged. The thymus weighed $1 \mathrm{~g}$. The ovaries were very small. The spleen was enlarged and weighed $180 \mathrm{~g}$. The other organs appeared normal. The brain weighed 1,070 g. fresh. Coronal sections through the fixed hemispheres showed normal sized ventricles and no obvious abnormality. The cerebellum was small and firm. The spinal cord looked normal.

CASE 3 S.R., a girl aged 12 (Maudsley no. 2456), had measles and pneumonia at the age of 8 months and since then had numerous attacks of pneumonia. She learnt to walk late and was never able to run well. From the age of 3 years she became progressively more unsteady on her feet so that she was unable to walk unaided by the time she was 9 years old. At this time there was a severe cerebellar ataxia, nystagmus, slurred speech, and sudden $\overline{\mathbb{Q}}$ tremors of the hands. She also had a slight right ptosis and early pes cavus. Sensation was normal. The right sternomastoid muscle was absent. On her final admission, aged 12, she had bilateral ptosis, eye movements were limited in all directions, the face lacked expression, and there was loss of position sense in addition to the cerebellar signs. The tendon reflexes were absent. She was small and there was weakness and wasting of muscles. This child never developed telangiectasia.

Family history The elder brother suffers from progressive ataxia and has developed telangiectases. He does not suffer from recurrent infections.

Investigations At the age of 11 the serum $\gamma$-globulin was reported to be decreased. At the age of 12 the electrophoretic pattern of $\gamma$-globulin was found to be abnormal in that the $\alpha_{2}$ and $\beta$ fractions were increased.

Necropsy findings The body was very wasted, the calves and small muscles of the hands being particularly affected. The right sternomastoid muscle was absent. The thymus was atrophied. The pleural cavities were oblitera- $\omega$ ted by adhesions. There was bullous emphysema, collapse of lung and bronchopneumonia. The tracheobronchial lymph nodes were enlarged. The right ventricle of the heart was hypertrophied. The other organs appeared normal. The brain weighed $1,250 \mathrm{~g}$. fresh. The cerebellum $\sigma$ was atrophied and felt firm. Coronal sections through the fixed cerebral hemispheres showed no abnormalities. The spinal cord looked normal but the posterior roots in the 음 cauda equina were grey and thinner than normal.

\section{HISTOLOGICAL FINDINGS}

These were extraordinarily similar in the three case The lungs showed evidence of past and recent infee tion. The liver showed fatty change, severe in case $\vec{\Gamma}$. There was round cell infiltration of the portal tracts. The kidneys showed small foci of inflammatory cells and areas of nephrocalcinosis. Heart, adrenals, thyroid, salivary glands, and pancreas appeared normal. There was severe atrophy of the testis in case 1 and of the ovaries in case 2. (The genital organs were not examined in case 3.) Lymph nodes showed loss of follicular pattern, reduction in number or absence of lymphoid follicles, reticulum cell hyperplasia, and large numbers of histiocytes. These often had large irregularly shaped nuclei. The spleen also showed loss of lymphoid follicles and hyperplasia of reticulum cells. Sections through the tissue from the region of the thymus in cases 1 and 2 showed very little thymic tissue. There was no cortical lymphoid tissue and no Hassall's corpuscles were seen. The thymus was not examined histologically in case 3 .

The pituitary gland of all three patients showed abnormalities. There were a number of large parenchymal cells with huge bizarre nuclei in the anterior lobe (Figs. 1 and 2). These giant cells were filled with $\mathcal{N}$ mucoid or acidophil granules and a large Golgi image $N$ could be seen in many. Most of the gland, however, 
looked normal. Unusually large pituicytes were seen in the posterior lobe.

MENINGES There were mild inflammatory changes, particularly in case 2 in which the walls of veins were affected. The leptomeninges over the cisterna magna were thickened and vascular in case 2 .

CEREBellum There was severe loss of Purkinje cells and granule cells (Fig. 3) most marked in the cerebellar vermis. Many Purkinje cells were abnormal. There were binucleated forms and some cells were situated in the middle of the molecular layer. The dendritic arborizations were abnormal, the branches being stout instead of slender and often containing a fine argentophilic network. An excess number of dendritic branches at abnormal angles were also noted (Fig. 4). Balls with spikes were seen on nerve fibres in the molecular layer occasionally and argentophilic swellings (torpedoes) were seen on nerve fibres in the granule cell layer (Figs. 5a and b). In two cases irregularly shaped eosinophilic inclusion bodies were found in the cytoplasm and dendrites of Purkinje cells (Fig. 6). The inclusion bodies stained red with the periodic acid-Schiff technique. There was gliosis in the cerebellar cortex but this was not severe. Bergmann glial cells were moderately increased in number but were not otherwise abnormal. The dentate nucleus was gliosed. No sudanophilic material was present in the cerebellum.

BRAIN-STEM There was gliosis in and around the inferior olives. Glial nodules (indicating nerve fibre degeneration) were seen in the pyramidal tracts and in the medial lemnisci (Fig. 7). The gracile nucleus was gliosed in case 1 , otherwise sections through midbrain and pons showed no obvious abnormalities.

CEREBRAL HEMISPHERES Sections including the basal ganglia, cerebral cortex and underlying white matter, and the subthalamic region, showed no obvious abnormalities, though there were occasional glial nodules (Fig. 7), a little round cell cuffing of vessels and a small amount of perivascular sudanophilic material.

GLIA No abnormally shaped or enlarged glial nuclei were seen in the cerebellum or elsewhere in the central nervous system.

SPINAL CORD Loss of myelinated nerve fibres in the posterior columns, particularly in the fasciculus gracilis, was evident in all three cases, most marked in case 1 (Figs. 8a and b, 9 and 10). Glial nodules were present in the white matter in other tracts. The grey matter looked normal. There was some sudanophilic material in the posterior horns of case 3.

DORSAL ROOT GANGLIA These were abnormal in all cases. There were markedly fewer satellite cells than normal and many had large oddly shaped nuclei and more cytoplasm than normal (Figs. 11a and b, and 12). There were no accumulations of satellite cells (nodules of Nageotte). The nerve cells were smaller than normal; their number was not assessed. These abnormalities were seen in cervical and lumbar dorsal root ganglia and in the Gasserian ganglia. In the peripheral nerves and nerve roots some Schwann cell nuclei appeared to be larger, particularly longer than normal, but the changes were not very striking.

SYMPATHETIC GANGLIA Cervical sympathetic and/or coeliac ganglia were available for examination in each case. There were fewer satellite cells than normal and the Schwann cells in the sympathetic trunks were reduced in number and had abnormally shaped nuclei (Figs. 13a and b, 14a and b). Nerve cells in the pericardium and in the wall of the gut and the bladder looked normal.

SKELETAL MUSCLES The muscle fibres were generally small in all three cases. In cases 1 and 3 there was clear-cut denervation atrophy (Fig. 15), most marked in distal muscles. In case 1 the lumbrical muscles of the hand showed denervation atrophy and the motor innervation was abnormal in that there was branching of the terminal nerve fibres (Fig. 16) which innervated more than one muscle fibre. This is regarded as evidence of partial denervation (Wohlfart, 1957). In case 2 samples of diaphragm and pectoralis major only were examined and these were normal. The innervation of the muscle spindles (examined only in case 1) was probably abnormal, fine leashes of beaded nerve fibres being present in some (Fig. 17).

SUMMARY OF THE MAIN HISTOLOGICAL FINDINGS

There was atrophy of the cerebellar cortex with loss of Purkinje and granule cells. Many Purkinje cells had abnormal processes. There were inclusion bodies in some. The number of satellite cells in sensory and autonomic ganglia was reduced. Many satellite cells had large nuclei and excess cytoplasm. Large Schwann cell nuclei were present in peripheral nerves and sympathetic trunks. There was loss of myelinated nerve fibres in the posterior columns of the spinal cord. Denervation atrophy of the distal skeletal muscles was seen. Giant acidophil and mucoid cells were seen in the anterior lobe of the pituitary. There was reticulum cell hyperplasia and lack of lymphoid follicles in lymph nodes and spleen. The thymus and the ovaries or testes were atrophied. 


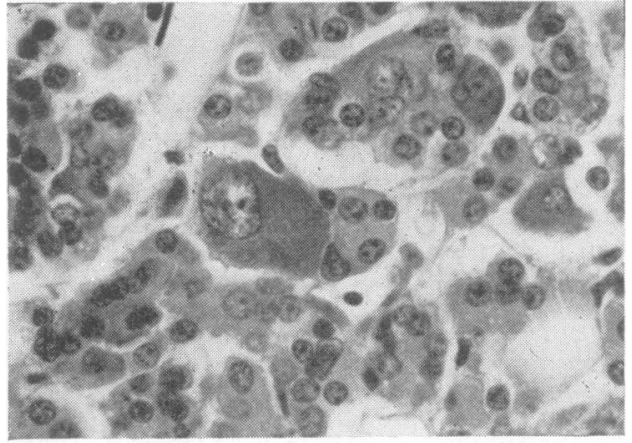

FIG. 1.

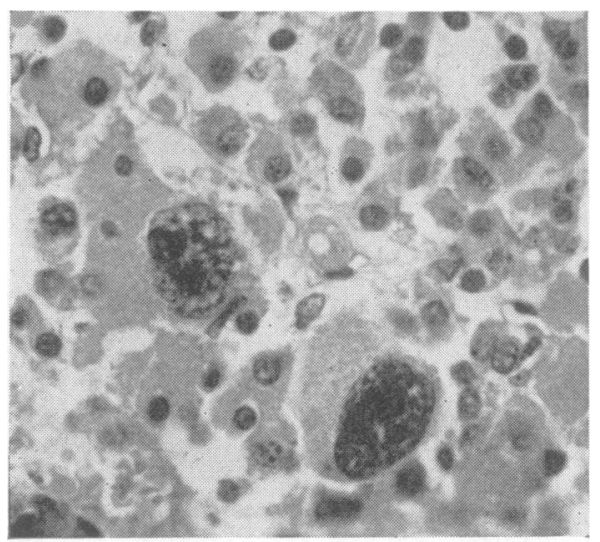

FIG. 2.

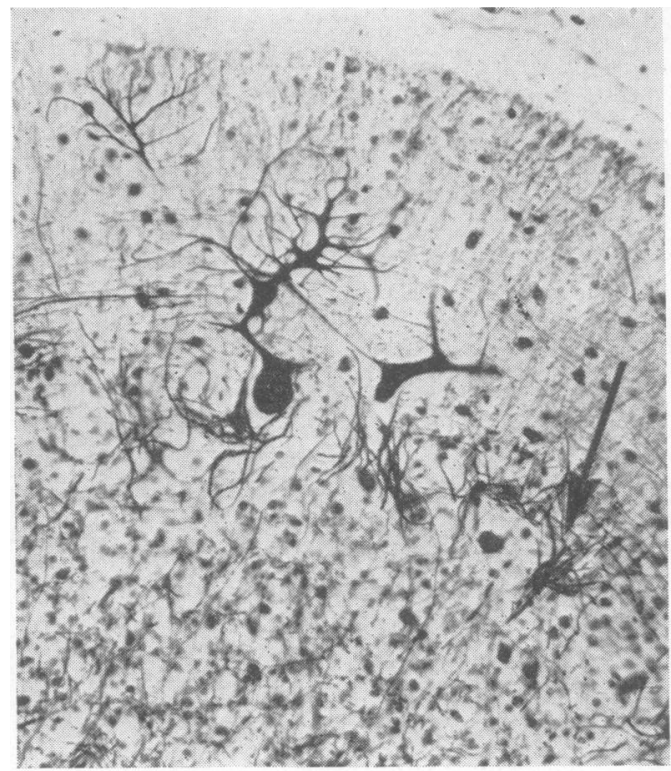

FIG. 4.

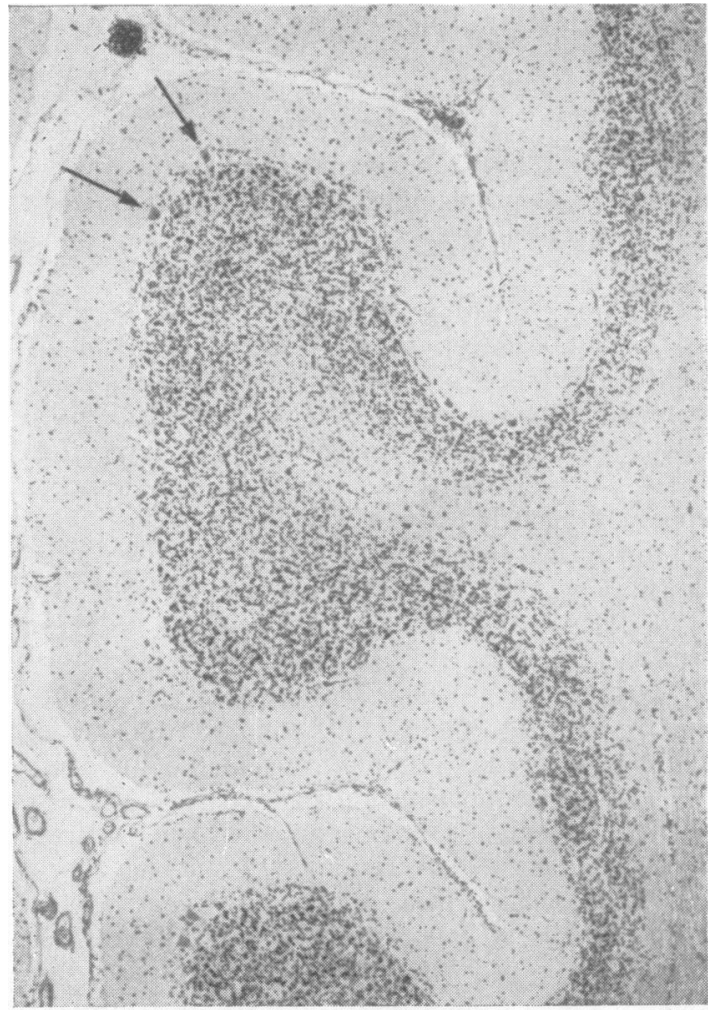

FIG. 3.

FIG. 1. Anterior lobe of pituitary gland of case 2. One large mucoid cell with a large nucleus is seen. (P.A.S./ Orange $G \times 420$.)

FIG. 2. Anterior lobe of pituitary gland of case 3. Two large acidophil cells with huge nuclei are present. (P.A.S.) Orange $G \times 420$.)

FIG. 3. Cerebellum of case 1. The Purkinje cells are markedly reduced in number (arrows to two remaining cells). There is loss of nerve cells in the granule cell layer. (Haematoxylin and eosin $\times$ 45.)

FIG. 4. Cerebellum of case 1. A Purkinje cell with an abnormal dendritic arborization. 'Empty baskets' can also be seen (arrow). (Palmgren $\times 190$.) 


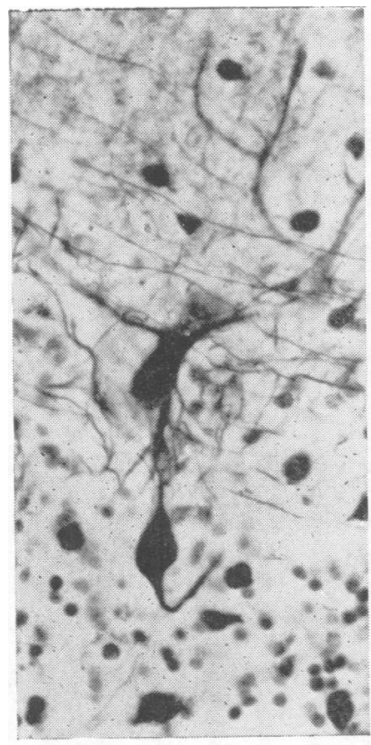

FIG. $5 a$.

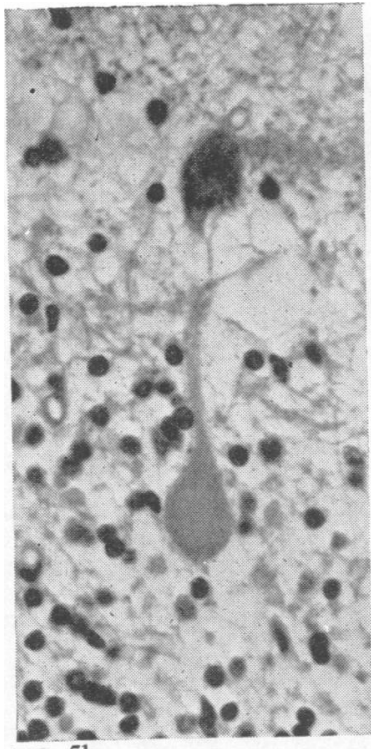

FIG. 5 b.
FIG. 6.
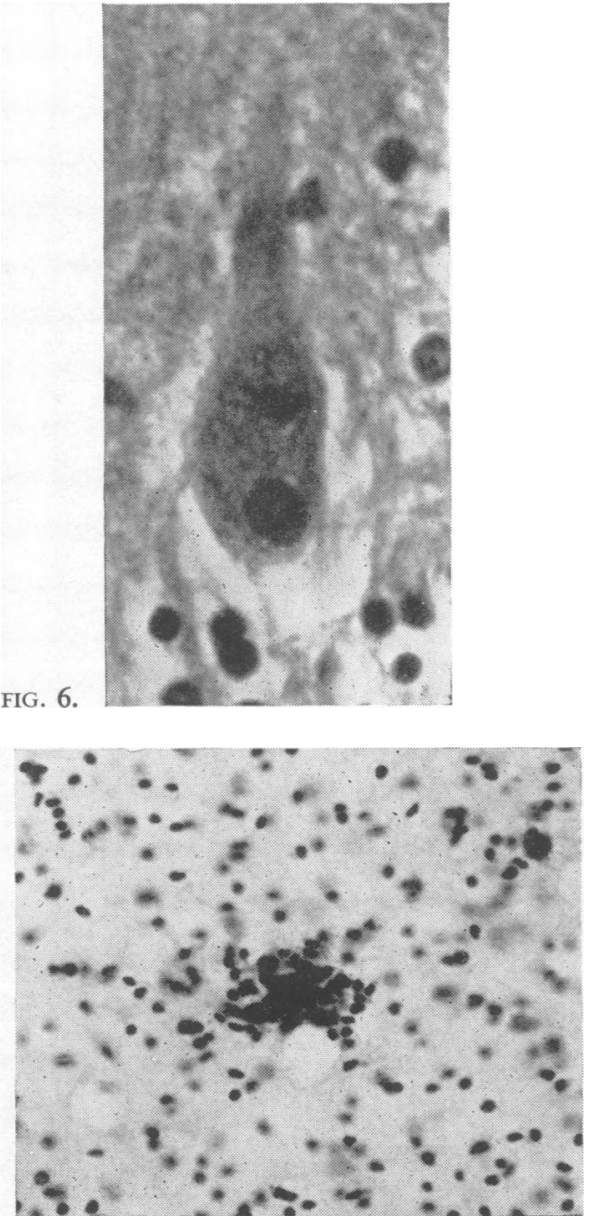

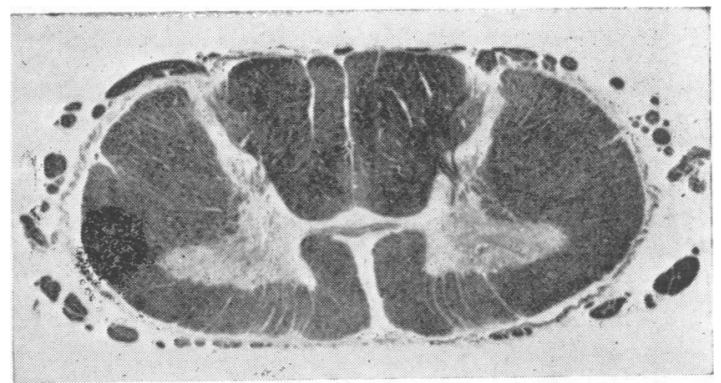

FIG. 8a.

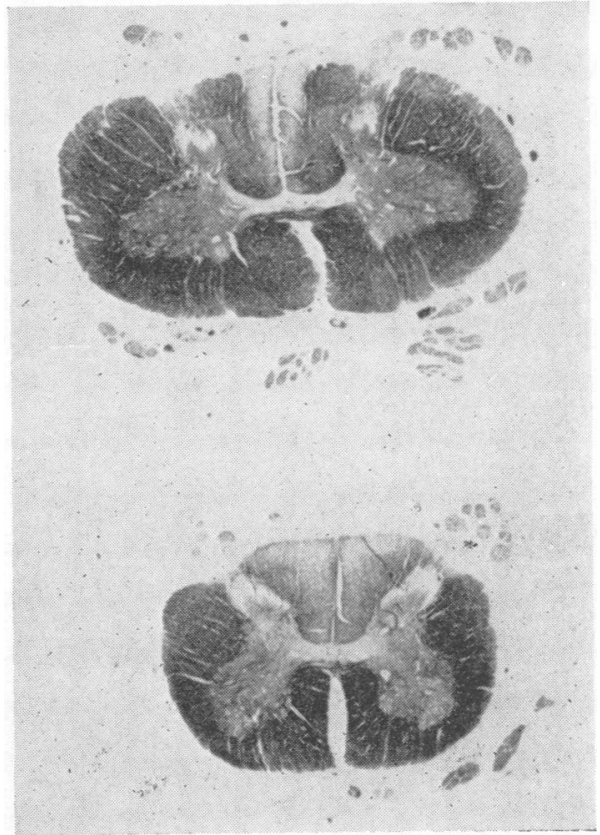

FIG. 8 b.

FIG. 5. Cerebellum of case 3.

(a) There is an argentophilic swelling (torpedo) on a nerve fibre in the granule cell layer. (Palmgren $\times 300$.)

(b) A similar swelling to that seen in Fig. 5a but stained with haematoxylin and eosin $\times 360$.

FIG. 6. Cerebellum of case 3. A Purkinje cell with an eosinophilic inclusion body is shown. (Haematoxylin and eosin $\times 600$.)

FIG. 7. Central white matter of case 3. A glial nodule can be seen. (Cresyl violet $\times 240$.)

FIG. 8a. Normal cervical spinal cord of a 16-year-old girl. Note the size of the posterior columns and the dark colour of the myelin. Paraffin section. Luxol-fast-blue/cresyl violet $\times 3 \cdot 8$.

b. Cervical and lumbar spinal cord of case 1. There is severe myelin loss in the posterior columns particularly in the fasciculus gracilis. The whole cord is smaller than normal.

Paraffin section. Luxol-fast-blue/cresyl violet $\times 3 \cdot 8$. 


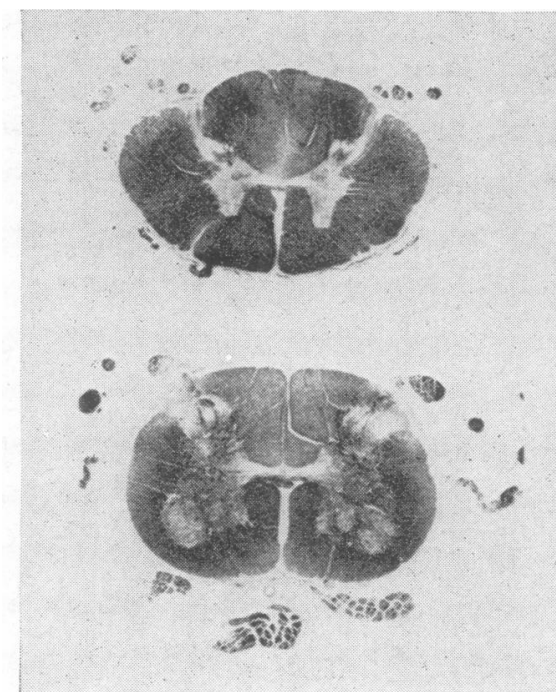

FIG. 9.
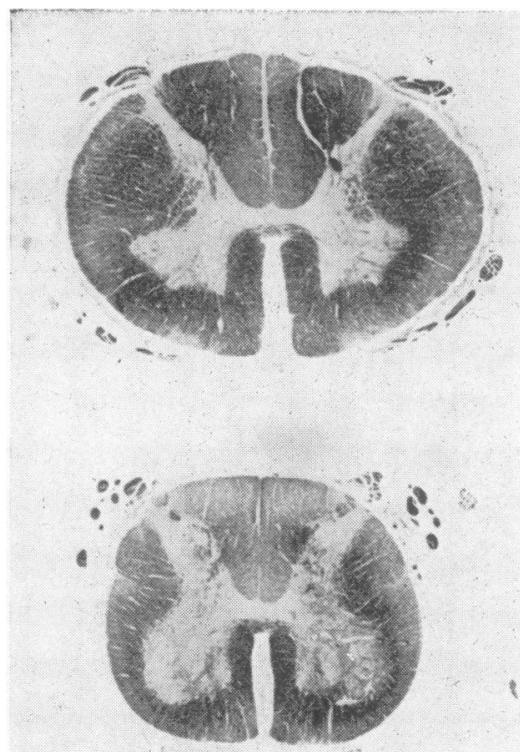

FIG. 10. Lumbar and case 3. The posterior columns are somewhat pale and the spinal cord is small compared with normal in Figure 8a. (Paraffin section. Luxol-fast-blue/cresyl violet $\times 3.8$.) columns, more marked in

FIG. 10.

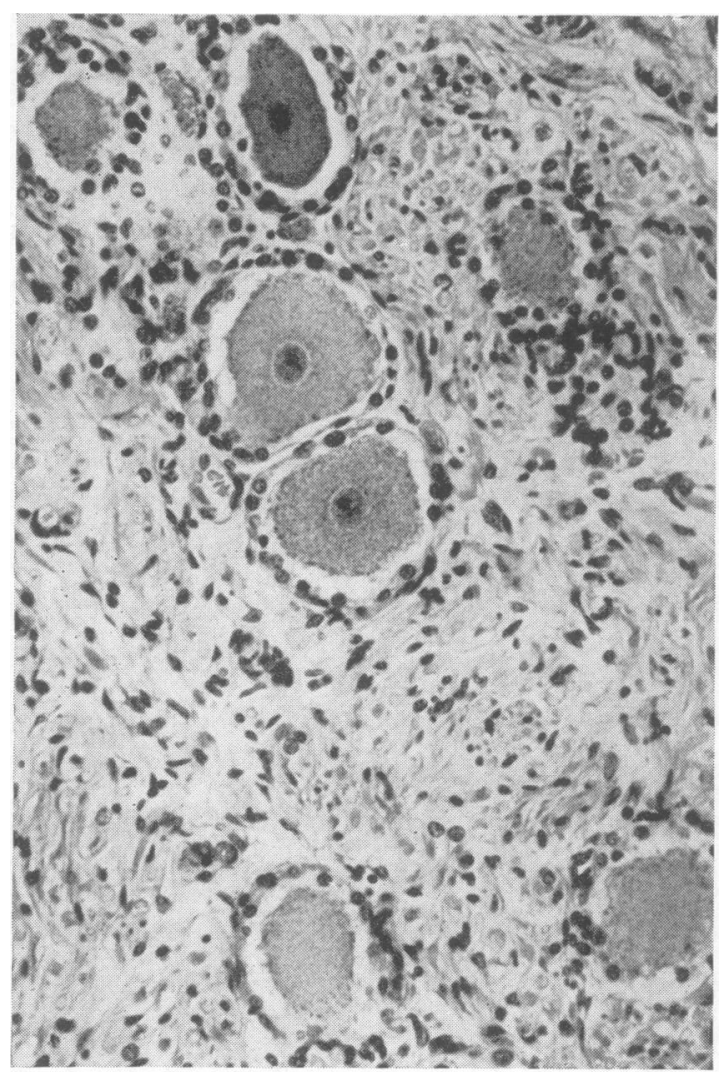

FIG. 11a.

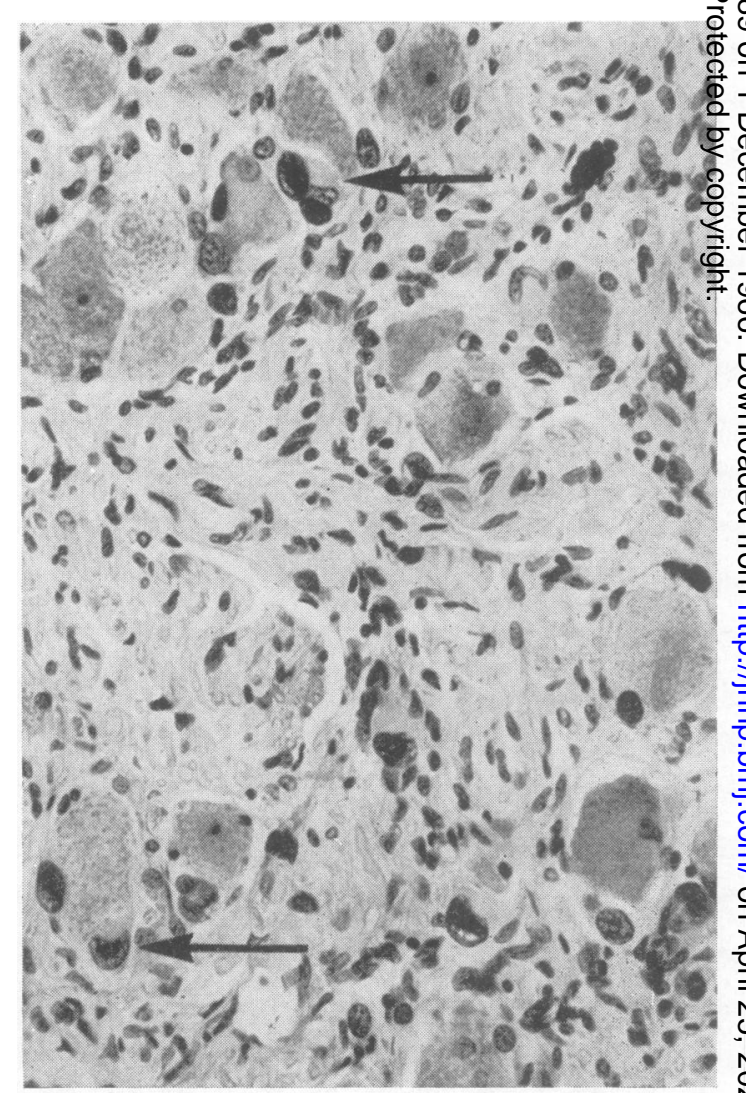

FIG, 11b. cervical spinal cord of

thoracic spinal cord of Paraffin section. Luxol-fastblue/cresyl violet $\times 3 \cdot 8$.

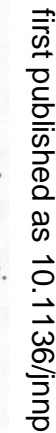

6 


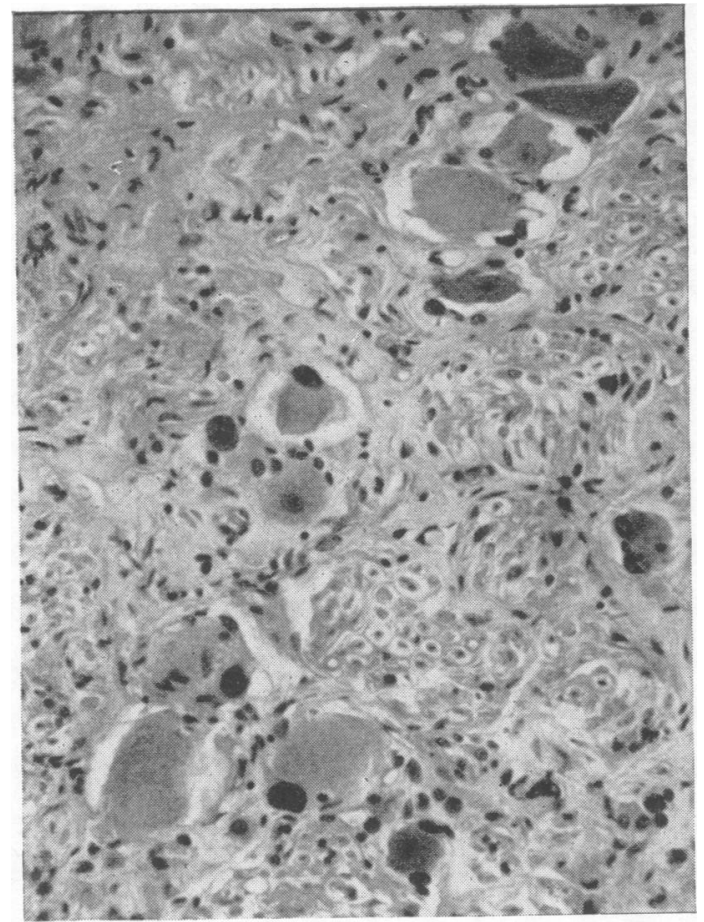

FIG. 12.

FIG. 11a. Normal dorsal root ganglion. Each nerve cell is surrounded by a capsule of satellite cells with small, uniform nuclei and little cytoplasm. (Haematoxylin and eosin $\times 240$.)

FIG. 11b. Dorsal root ganglion of case 1. The nerve cells are smaller than normal. Satellite cells are few in number; many (arrows) have large, oddly shaped nuclei and excess cytoplasm. The Schwann cells in the ganglion are more pleomorphic than in the normal. Compare with Figure 11a. (Haematoxylin and eosin $\times 240$.)

FIG. 12. Dorsal root ganglion from case 2. The satellite cells are markedly reduced in number and many have very large nuclei. Compare with Figure 11a. (Haematoxylin and eosin $\times 200$.)

FIG. 13a. Normal cervical sympathetic ganglion. Notice the small, rather uniform satellite cells and Schwann cells. (Haematoxylin and eosin $\times 240$.)

FIG. 13b. Cervical sympathetic ganglion of case 1. Many of the nuclei of Schwann cells and satellite cells are enlarged. (Haematoxylin and eosin $\times 240$.)

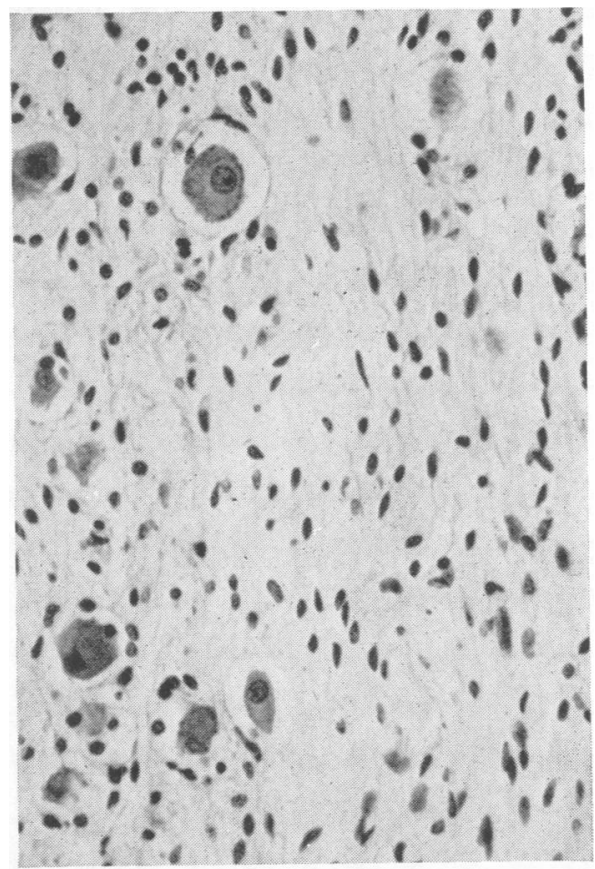

FIG. 13a.

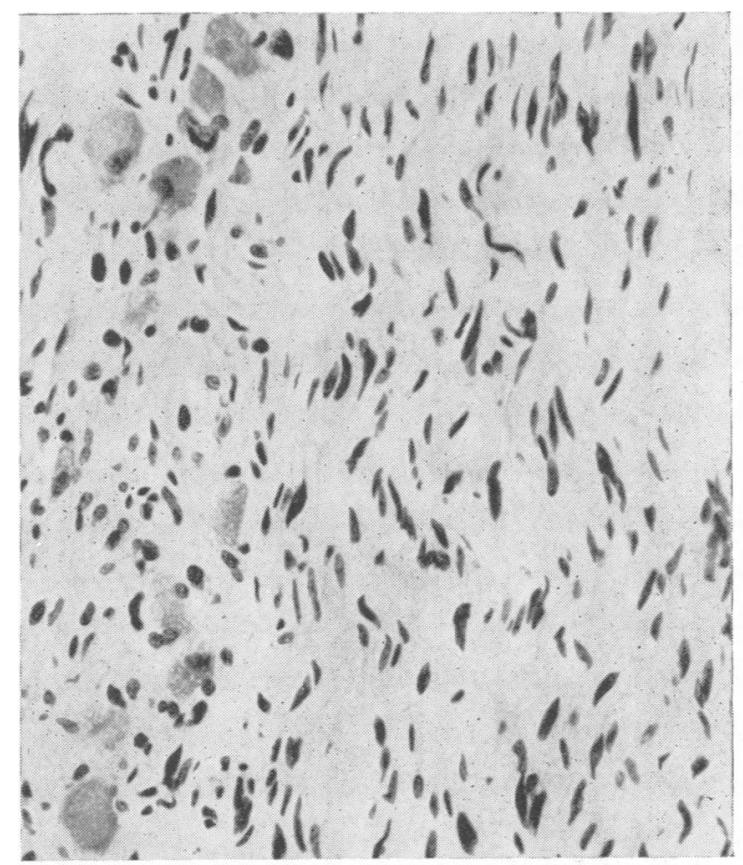

FIG. 13b. 


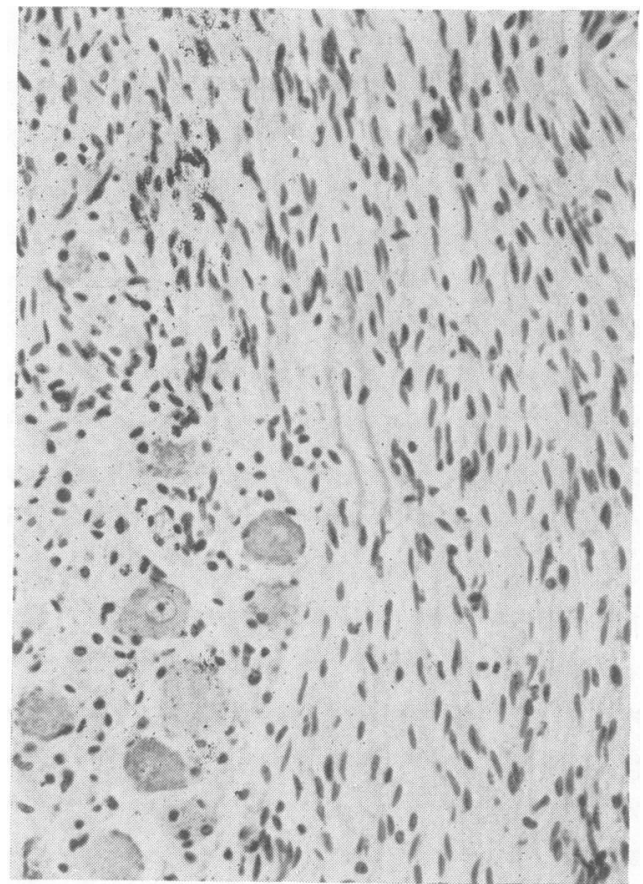

FIG. $14 \mathrm{a}$.

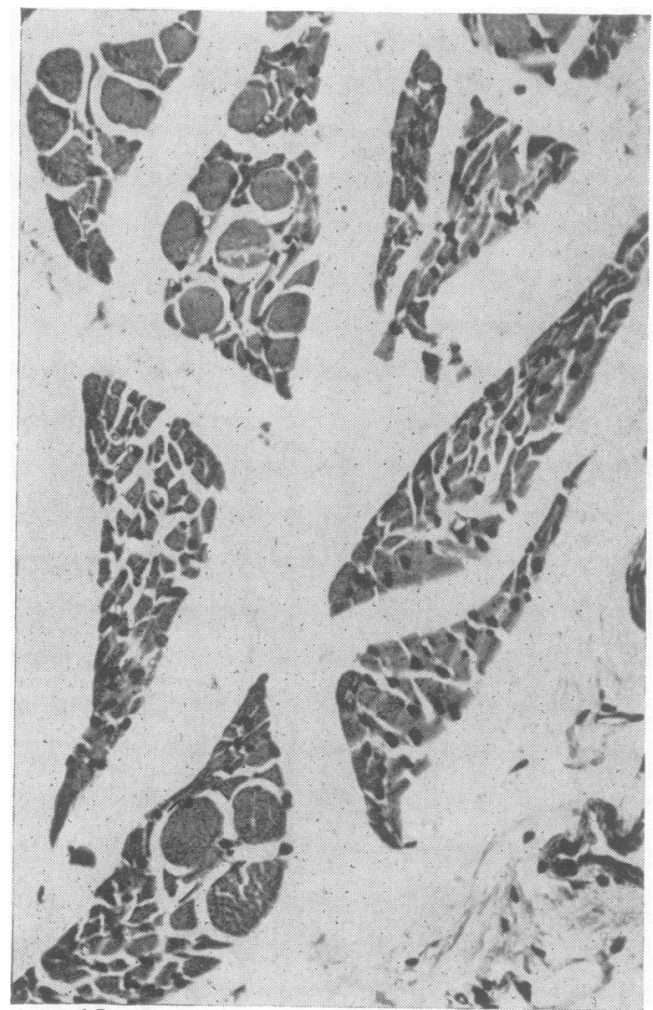

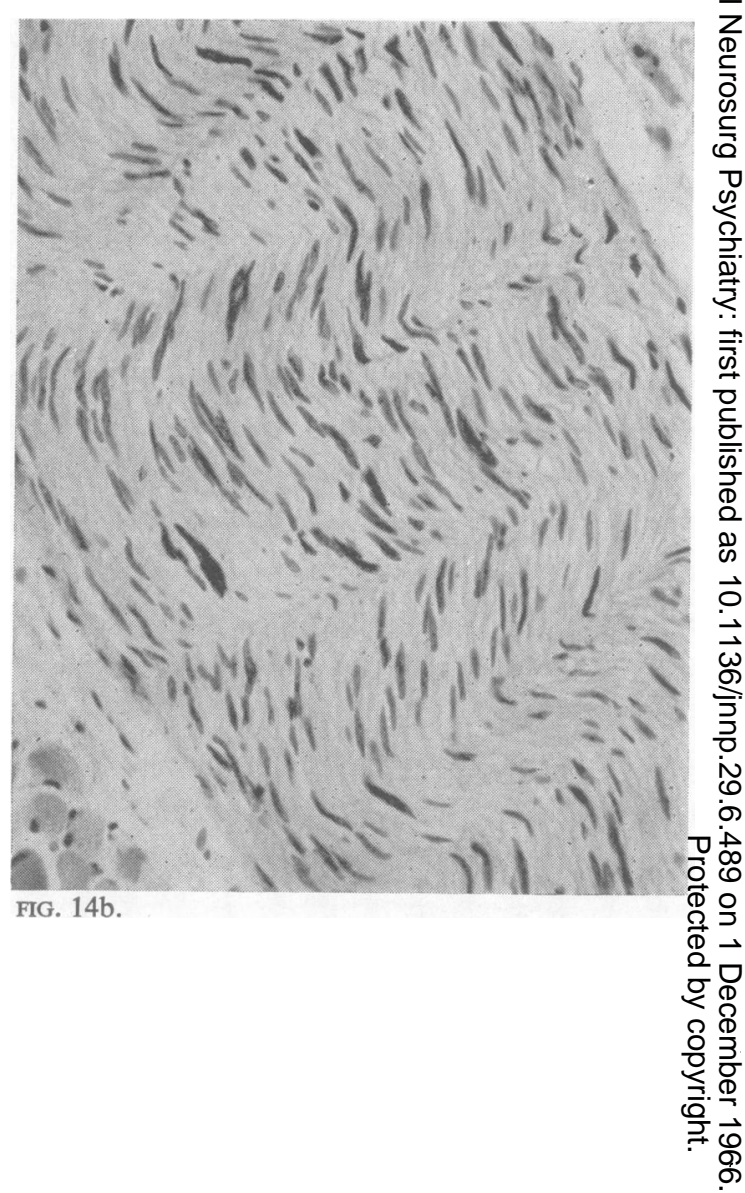

FIG. 14a. Normal coeliac ganglion to show nerve cells and the size and number of Schwann cell nuclei in the nerve trunk. (Haematoxylin and eosin $\times 190$.)

FIG. 14b. Nerve trunk leading into the coeliac ganglion of case 2. The Schwann cell nuclei are larger than in the normal. (Haematoxylin and eosin $\times 190$.)

FIG. 15. Transverse section through the flexor carpi ulnaris of case 3 to show denervation atrophy. There are bundles of small muscle fibres and a few groups of normal sized muscle fibres. (Haematoxylin and eosin $\times 275$.) 


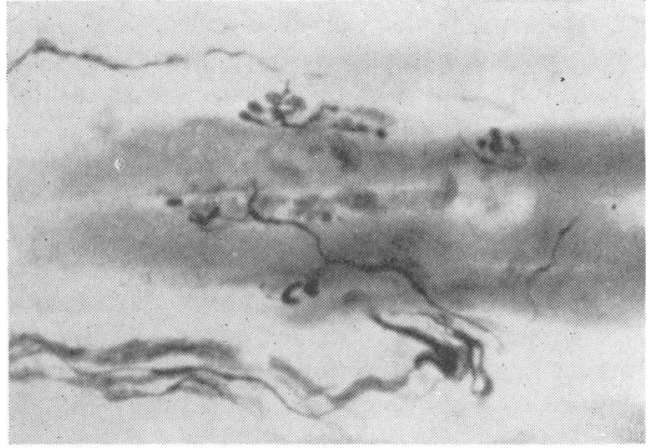

FIG. 16.

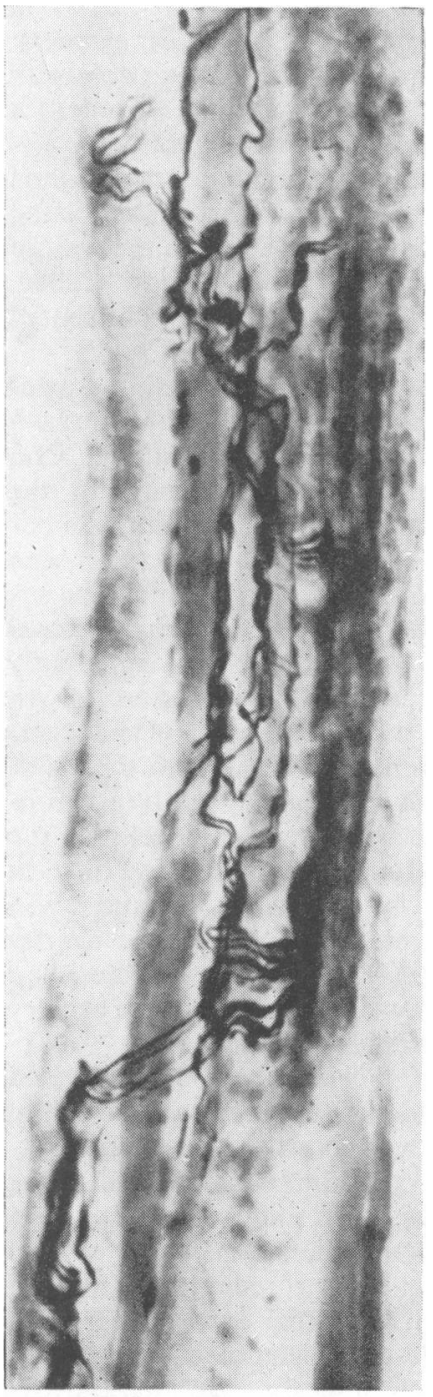

FIG. 17.

\section{DISCUSSION}

From these three case histories and a perusal of the literature on ataxia-telangiectasia (summarized by Boder and Sedgwick, 1964; and Karpati, Eisen, Andermann, Bacal, and Robb, 1965) it will be seen that the signs and symptoms of this disease are very stereotyped. There is a high familial incidence, the mode of inheritance being that of an autosomal recessive character (Tadjoedin and Fraser, 1965). The first sign is a progressive cerebellar ataxia, beginning in early childhood. Some years later telangiectases appear on the bulbar conjunctivae and elsewhere. Other clinical signs present in most cases are abnormal eye movements, loss of tendon reflexes, athetoid movements and myoclonic jerks, a stooping posture, mask-like face, drooling of saliva, retardation of growth, lack of sexual development, and greying of hair or pigmentation of skin. Intellectual deterioration usually occurs in the later stages of the disease, and weakness and wasting of skeletal muscles may develop. Some $85 \%$ of patients suffer from frequent infections of the middle ears, air sinuses, and lungs (but not of other organs), and a proportion of patients have a serum $\gamma$-globulin deficiency and abnormal immunological responses (Fireman, Boesman, and Gitlin, 1964; Peterson, Kelly, and Good, 1964; Rosenthal, Markowitz, and Medenis, 1965). The pathological changes as described in the present paper are equally constant and involve the spino-cerebellar system, the satellite cells of sensory and autonomic ganglia, Schwann cells of peripheral nerves and sympathic trunks, and cells in the pituitary gland; in addition the lymphoid tissue and thymus are abnormal.

It is at present impossible to propose a common cause or causes for these abnormalities. It has been suggested that the degeneration in the nervous system is due to telangiectases but there were no vascular malformations in the peripheral or central nervous system of the present three cases and the few illustrations of dilated venules in the cerebellar white matter published by others (Boder and Sedgwick, 1958; Centerwall and Miller, 1958) do not provide convincing evidence of significant vascular anomalies.

The degeneration in the cerebellum involved granule cells and Purkinje cells. The remaining Purkinje cells often showed abnormal branching of their dendrites and swellings (torpedoes) on their axons (Figs. 4 and 5). These changes are also seen in other hereditary cerebellar degenerations and give no clues as to pathogenesis. Cases 2 and. 3 showed eosinophilic inclusion bodies in the cytoplasm of Purkinje cells (Fig. 6). These have not been described before either in ataxia-telangiectasia or in other cerebellar degenerations. 
The atrophy of the cerebellar cortex no doubt accounts for the cerebellar ataxia and dysarthria exhibited by these patients, but apart from this the correlation between clinical and pathological findings is unsatisfactory in ataxia-telangiectasia. No histological abnormalities to account for athetoid movements, deterioration of intellectual performance, or abnormal eye movements were found in the cerebral hemispheres or in the brain-stem. Other workers have reported a similar lack of abnormality in the brain apart from the cerebellum. Evidence of recent degeneration in various parts of the nervous system was seen in the form of occasional glial nodules and mild round cell cuffing of blood vessels in all three cases, but one cannot say whether this is part of the hereditary disease or a non-specific reaction in the brain of an ill person.

In the sensory and autonomic ganglia there were markedly fewer satellite cells than normal and many were enlarged and had big, bizarre nuclei (Figs. 11 to 14). Such changes have not to my knowledge been described before in any disease. The functional significance of these abnormalities in sensory ganglia is not known. In the present cases sensation was apparently normal, except in one child (case 3) who showed some loss of position sense towards the end of her illness. The tendon reflexes, however, were absent in two patients and diminished in one. According to a table compiled from the literature by Boder and Sedgwick (1964), normal sensation, an absent Romberg sign, but progressive loss of tendon reflexes are the usual findings in patients with ataxiatelangiectasia.

Degeneration of sensory and motor nerve fibres certainly occurs eventually in ataxia-telangiectasia as evidenced by loss of myelinated nerve fibres in the posterior columns of the spinal cord seen in each of the three patients and denervation atrophy of distal skeletal muscles noted in two. There was no obvious loss of anterior horn cells and the motor nerve fibre degeneration may be related to abnormal Schwann cells in the peripheral nerve. The innervation of muscle spindles was probably abnormal. There were fine leashes of nerve fibres, possibly the result of reinnervation after sensory denervation. Conduction velocities have been measured in peripheral nerves by Dunn, Meuwissen, Livingstone, and Pump (1964) who reported them as being on the lower limit of normal and by Karpati et al. (1965) who found them to be normal. The possibility that some of the abnormal reflexes and abnormal movements seen in patients with ataxia-telangiectasia may be related to abnormal conduction of impulses through spinal ganglia seems worth investigating.

Abnormal pigmentation and café au lait spots which occur in ataxia-telangiectasia are of interest because Schwann cells, satellite cells, and skin pigment cells have a common origin from the neural crest which may be one of the sites of the abnormal gene action.

Although Schwann cells and satellite cells were abnormal in the sympathetic trunk and ganglia in all three cases (Figs. 13 and 14), there were no obvious signs of autonomic dysfunction except dryness of the skin and mouth in the first case and perhaps drooling of saliva in the second. One wonders whether an abnormality in mucus secretion is a factor in the lack of resistance to respiratory tract infection which is so common in ataxia-telangiectasia. Recurrent pulmonary infections are a constant feature of fibrocystic disease of the pancreas (mucoviscidosis) in which an abnormally viscid mucus is secreted. Frequent lung infections also occur in patients with familial dysautonomia (Riley-Day syndrome), a condition in which there are obvious autonomic disturbances. Very few cases of familial dysautonomia have been investigated pathologically but vacuolated nerve cells in sympathetic ganglia and in the wall of the gut have been reported (Solitare and Cohen, 1965); the satellite cells have not been commented upon.

The endocrine system is also implicated in ataxia telangiectasia, for small stature and failure to reach sexual maturity are common even in patients who have not had severe recurrent infections. In the present three cases a number of very large mucoid or acidophil cells with very large nuclei were seet in the anterior lobe of the pituitary gland. The sex organs were atrophied but the thyroid and adrenaF glands looked normal histologically. This apparently selective abnormality in gonadotrophic and growth hormone activity has to be confirmed by endocrine studies during life before correlation with the histological abnormalities in the pituitary can be attempted. Very large acidophil and mucoid cells in the anterior lobe of the pituitary have been described in ataxia-telangiectasia by Bowden, Danis, and Sommers (1963) in a patient with atrophic ovaries and by Dunn et al. (1964) in a patient who also had an ovarian dysgerminoma and in whom the urinary excretion of 17-ketosteroids was low.

A serum $\gamma$-globulin deficiency was demonstrated at some stage of the illness in all three patients and in case 2 the deficiency was shown to be of the $\gamma$-Afraction. A serum $\gamma$-globulin deficiency affecting $\gamma$-A-globulin mainly has been found in a proportion of patients with ataxia-telangiectasia by others (Gutmann and Lemli, 1963; Fireman et al., 1964; Peterson et al., 1964; Rosenthal et al., 1965). The relation between lack of resistance to respiratory tract infection and levels of serum $\gamma$-globulin is by no means clear cut. Only a few cases have been investi然 
gated so far, but children with ataxia-telangiectasia and troublesome infections have usually had a low serum $\gamma$-globulin at some stage. An atrophic thymus, reticulum cell hyperplasia with poorly developed lymphoid follicles in lymph nodes and spleen were seen in the present three cases and this is in accord with the findings of other authors (Fireman et al., 1964; Peterson et al., 1964). Several children have developed one of the malignant reticuloses (see Peterson et al., 1964).

Immunological competence has been tested in a number of patients and their relatives but the results are contradictory (Peterson et al., 1964; Fireman et al., 1964; Rosenthal et al., 1965). The ability to make circulating antibodies is probably not impaired but the delayed hypersensitivity reaction and skin graft rejection may be abnormal.

A number of other abnormalities have been reported in patients with ataxia-telangiectasia. These include sacral spina bifida (with hypospadias and undescended testes), hemivertebra, abnormal axis and atlas (case 1), club foot, syndactyly, and absence of sternomastoid muscle (case 3). Whether these are incidental findings or are a part of the genetic aberration remains to be seen.

The disease affects the central and peripheral nervous system, the skin, the anterior lobe of the pituitary and the mechanisms involved in resisting respiratory tract infections. There is a certain lack of correlation between functional abnormalities and structural abnormalities. This only serves to emphasize the fact that in ataxia-telangiectasia, as in most other hereditary diseases, the fundamental defect eludes us.

\section{SUMMARY}

The clinical histories and pathological findings in three cases of ataxia-telangiectasia are reported.

Clinically the cases conform to the typical pattern with progressive cerebellar ataxia, cutaneous telangiectases, involuntary movements, loss of tendon reflexes, intellectual deterioration, small stature, etc. All three patients suffered from frequent pulmonary infections and a serum $\gamma$-globulin deficiency was demonstrated.

The significant histological abnormalities in the central nervous system were a severe degeneration of the cerebellar cortex and loss of myelinated nerve fibres in the posterior columns of the spinal cord. Some Purkinje cells contained cytoplasmic inclusion hodies.

In the peripheral nervous system there were abnormalities which have not been described before. Satellite cells in the posterior root ganglia and in sympathetic ganglia were reduced in number compared to normal; many satellite cells were large and had big, oddly shaped nuclei. Schwann cells in peripheral and autonomic nerves were also enlarged. There was motor denervation of distal skeletal muscles.

Giant acidophil and mucoid cells were present in the anterior lobe of the pituitary and the sex organs were atrophied.

Patients 1 and 3 were looked after during life by Dr. M. J. Wilmers, King's College Hospital and patient 2 by Professor J. P. M. Tizard, Hammersmith Hospital. I am grateful for permission to use the case records. Thanks are due to Mr. A. R. Salliss and his staff for the technical work and to Mr. P. M. Taylor for the photographs. The expenses of this investigation were defrayed by grants from the Nuffield Foundation and from the Associations of Muscular Dystrophy of America, Inc.

\section{REFERENCES}

Boder, E., and Sedgwick, R. P. (1958). Ataxia-telangiectasia. A familial syndrome of progressive cerebellar ataxia, oculocutaneous telangiectasia and frequent pulmonary infection. Pediatrics, 21, 526-554.

- - (1963). Ataxia-telangiectasia. A review of 101 cases.

In Cerebellum Posture and Cerebral Palsy, edited by G. Walsh. p.p. 110-118 (Little Club Clinics in Developmental Medicine No. 8). Heinemann, London.

-, (1964). Ataxia-telangiectasia. A review of 150 cases. In International Copenhagen Congress on the Scientific Study of Mental Retardation, Proceedings. Vol. 2., pp. 798-802.

Bowden, D. H., Danis, P. G., and Sommers, S. C. (1963). Ataxiatelangiectasia. A case with lesions of ovaries and adenohypophysis. J. Neuropath. exp. Neurol., 22, 549-554.

Centerwall, W. R., and Miller, M. M. (1958). Ataxia, telangiectasia, and sinopulmonary infections. Amer. J. Dis. Child., 95, 385-396.

Dunn, H. G., Meuwissen, H., Livingstone, C. S., and Pump, K. K. (1964). Ataxia-telangiectasia. Canad. med. Ass. J., 91, 11061118.

Fireman, P., Boesman, M., and Gitlin, D. (1964). Ataxia-telangiectasia : A dysgammaglobulinaemia with deficient $\gamma_{1} \mathbf{A}\left(\beta_{2} \mathbf{A}\right)$-globulin. Lancet, 1, 1193-1195.

Gutmann, L., and Lemli, L. (1963). Ataxia-telangiectasia associated with hypogammaglobulinemia. Arch. Neurol. (Chic.), 8, 318327.

Karpati, G., Eisen, A. H., Andermann, F., Bacal, H. L., and Robb, P. (1965). Ataxia-telangiectasia. Amer. J. Dis. Child., 110, 51-63.

Louis-Bar, (1941). Sur un syndrome progressif comprenant des télangiectasies capillaires cutanées et conjonctivales symétriques à disposition naevolde et des troubles cérébelleux. Confin. neurol. (Basel), 4, 32-42.

Palmgren, A. (1948). A rapid method for selective silver staining of nerve fibres and nerve endings in mounted paraffin sections. Acta zool. (Stockh.), 29, 377-392.

Peterson, R. D. A., Kelly, W. D., and Good, R. A. (1964). Ataxiatelangiectasia, its association with a defective thymus, immunological-deficiency disease and malignancy. Lancet, 1, 1189-1193.

Rosenthal, I. M., Markowitz, A. S., and Medenis, R. (1965). Immunologic incompetence in ataxia-telangiectasia. Amer.J. Dis. Child., 110, 69-75.

Solitare, G. B., and Cohen, G. S. (1965). Peripheral autonomic nervous system lesions in congenital or familial dysautonomia. Riley-Day syndrome. Neurology (Minneap.), 15, 321-327.

Schofield, G. C. (1960). Experimental studies on the innervation of the mucous membrane of the gut. Brain, 83, 490-512.

Tadjoedin, M. K., and Fraser, F. C. (1965). Heredity of ataxiatelangiectasia (Louis-Bar syndrome). Amer. J. Dis. Child., 110, 64-68.

Wohlfart, G. (1957). Collateral regeneration from residual motor nerve fibers in amyotrophic lateral sclerosis. Neurology, (Minneap.), 7, 124-134. 